\title{
Treating the Oral Creeper: Herpes
}

\author{
Yadav Karthik D ${ }^{1 *}$, Pai Anuradha², R Shesha Prasad ${ }^{3}$, Yaji Anisha ${ }^{4}$ \\ ${ }^{1}$ M.D.S - Master of Dental surgery, Department of oral medicine and radiology, Bangalore \\ ${ }^{2}$ HOD \& Professor, Department of oral medicine and radiology, The oxford dental college and research center, Bangalore \\ ${ }^{3}$ M.D.S - Master of Dental surgery, Department of oral medicine and radiology, Senior lecturer, The oxford dental college and research center, Bangalore \\ ${ }^{4}$ M.D.S - Master of Dental surgery, Department of oral medicine and radiology, Bangalore
}

Received: 制 August 19, 2018; Published: 非 August 24, 2018

*Corresponding author: Karthik D Yadav, $10^{\text {th }}$ Milestone, Bommanahalli, Hosur Road, Bangalore-560 102, India

\section{Short Communication}

The term "herpes" creates panic among the general population. Oral herpes simplex virus is most commonly seen affecting the oral soft tissue region the perioral area [1,2]. They have been categorized into HSV -1 and HSV -2, wherein HSV-1 affects the orofacial region, most commonly above the waist region and HSV-2 affects the genital region below the waist. However, change in sexual practices have been the basis for the variations of the virus, affecting the non-conventional regions of the body $[3,4]$. The primary oral form is most commonly seen in children with prodromal symptoms manifesting as malaise, fever and lymphadenopathy followed at the later phase as vesicles or ulcers or both within the oral cavity and usually resolves within duration of two weeks [3]. The history, sign and symptoms are sufficient to reach a diagnosis. The use of laboratory investigations is usually not mandatory [2,5]. Palliative and supportive care remains the mainstay of the treatment [3].

The virus then remains latent within the trigeminal nerve ganglion and might be reactivated by stress, illness or any environmental conditions, which results in recurrence of the disease [3]. When the lesions are clinically evident it is termed as recrudescent HSV infection [1,3]. The lesions that are seen at the muco-cutaneous junction of the lips is termed as fever blister or cold sore. Sometimes the patients also experience other prodromal symptoms prior to RHL, which comprises of pain, itching and burning at the site of lesion [6].

Over the years both topical and systemic therapies have been tried. Both the treatment modalities have their benefit to adverse effects ratio. The topical therapies can be further categorized into palliative, preventive and antiviral categories.

Under palliative treatment, the over the counter drugs which are available for the treatment of herpes is benzocaine, which helps in decreasing the pain in relation to intraoral HSV infection, whereas the drugs available by prescription include lidocaine alone (gel $2 \%$ or viscous lidocaine $2 \%$ ) or sometimes in combination with coating agents and also with/without diphenhydramine. A combination of all these drugs is more effective in treating HSV infections than the anesthetic preparations alone. They are also used with systemic antiviral agents for increased efficacy while treating HSV. Further, ice can be used and lip materials containing cocoa, lanolin and petroleum products have been recommended to treat recurrent herpes [6].

While the use of topical drugs has few adverse effects and are preferred over the systemic drugs, however they should not be neglected as some serious life-threatening conditions have been reported $[7,8]$. These events include neurologic and cardiovascular response on aspiration of lidocaine which are manifested as seizures and hypotensive occurrences, while ingestion of topical benzocaine has manifested on the progress to methemoglobinemia [8-11]. These adverse effects have led to the non -usage of benzocaine and its product in children below 2 years of age, as suggested by Food and Drug Administration in 2011 [12]. Preventive agents such as sunscreen on lips with an SPF of at least 15 is advised when sun is considered as a risk factor in developing RHL $[4,13]$.

These Topical antiviral drugs have been reported to show maximum efficacy during the prodromal phase by reducing the healing time of the lesion [6]. The most common drugs are acyclovir $5 \%$, penciclovir $1 \%$ and docosanol $10 \%$ in cream form $[1,2,4,13]$. Other topical drug preparations of foscarnet, cidofivir and imiquimod are only used when the treatment of RHL have found to be resistant and non-responsive to the conventional antiviral drugs which include acyclovir $5 \%$ cream, penciclovir $1 \%$ cream and docosanol $10 \%$ cream $[14,15]$.

Systemic agents are used for treatment and prophylaxis of both RHL and RIH. The benefits of systemic over topical drugs include greater drug exposure, rapid access to site of viral replication, better biocompatibility less frequent dosing and improved compliance $[16,17]$. Treatment of primary oral HSV infection is by supportive and symptomatic interferences [18]. Accelerated healing with reduction in viral load and improved oral intake was 
seen in pediatric patients who were treated with oral acyclovir suspension at a dosage of $15 \mathrm{mg} / \mathrm{kg}$ within 3 days of symptom onset and continued five times a day for one week [19]. Newer antiviral medications such as famciclovir and valacyclovir may also be prescribed given their more convenient dosing and increased bioavailability [14].

Systemic antiviral medications may be used for prophylaxis as well as for treatment of patients with severe, recurrent, obstinate and hideous epidemics [20]. FDA has approved oral valacyclovir for the management of RHL [17]. Genital herpes is treated and suppressed by oral acyclovir and famiciclovir and have also been used for RHL therapy [13,21].

\section{Conclusion}

The realization and awareness of the disease process in the early stages helps in better treatment planning and reduced healing period. Several treatment modalities have certainly evolved over time and the availability of these has definitely helped in treating the disease process. However, more molecular level research can definitely help us in drawing much better treatment plans leading to successful treatment and a superior prognosis.

\section{References}

1. Arduino PG, Porter SR (2006) Oral and perioral herpes simplex virus type 1 (HSV-1) infection: Review of its management. Oral Dis 12(3): 254270.

2. Cunningham A (2012) Current management and recommendations for access to antiviral therapy of herpes labialis. J Clin Virol 53(1): 6-11.

3. Stoopler ET (2005) Oral herpetic infections (HSV 1-8). Dent Clin North Am 49(1): 15-29.

4. Fatahzadeh M, Schwartz RA (2007) Human herpes simplex labialis. Clin Exp Dermatol 32(6): 625-630.

5. Stoopler ET, Pinto A, DeRossi SS, Sollecito TP (2003) Herpes simplex and varicella-zoster infections: Clinical and laboratory diagnosis. Gen Dent 51(3): 281-286.

6. Fatahzadeh M, Schwartz RA (2007) Human herpes simplex virus infections: epidemiology, pathogenesis, symptomatology, diagnosis, and management. J Am Acad Dermatol 57(5): 737-763.

\section{ISSN: 2574-1241}

DOI: 10.26717/BJSTR.2018.08.001639

Karthik D Yadav. Biomed J Sci \& Tech Res

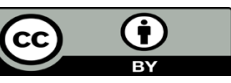

This work is licensed under Creative

Commons Attribution 4.0 License

Submission Link: https://biomedres.us/submit-manuscript.php
7. Faden H (2006) Management of primary herpetic gingivostomatitis in young children. Pediatr Emerg Care 22(4): 268-269.

8. So TY, Farrington E (2008) Topical benzocaine-induced methemoglobinemia in the pediatric population. J Pediatr Health Care 22(6): 335-339.

9. Hess GP, Walson PD (1988) Seizures secondary to oral viscous lidocaine. Ann Emerg Med 17(7): 725-727.

10. Garrett son LK, McGee EB (1992) Rapid onset of seizures following aspiration of viscous lidocaine. J Toxicol Clin Toxicol 30(3): 413-422.

11. Chung NY, Batra R, Itzkevitch M, Boruchov D, Baldauf M (2010) Severe methemoglobinemia linked to gel-type topical benzocaine use: A case report. J Emerg Med 38(5): 601-606.

12. Benzocaine topical products: Sprays, gels and liquids - risk of methemoglobinemia. U.S. Food and Drug Administration; U.S. Department of Health and Human Services, USA.

13. Woo SB, Challacombe SJ (2007) Management of recurrent oral herpes simplex infections. Oral Surg Oral Med Oral Pathol Oral Radiol Endod 103: e1-e18.

14. Balfour HH Jr (1999) Antiviral drugs. N Engl J Med 340: 1255-1268.

15. Hirokawa D, Woldow A, Lee SN, Samie F (2011) Treatment of recalcitrant herpes simplex virus with topical imiquimod. Cutis 88(6): 276-277.

16. Laiskonis A, Thune T, Neldam S, Hiltunen-Back E (2002) Valacyclovir in the treatment of facial herpes simplex virus infection. J Infect Dis 186: S66-S70.

17. Spruance SL (2003) High-dose, short-duration, early valacyclovir therapy for episodic treatment of cold sores: results of two randomized, placebo-controlled, multicenter studies. Antimicrob Agents Chemother 47(3): 1072-1080.

18. Lynch DP (2000) Oral viral infections. Clin Dermatol 18: 619-628.

19. Amir J, Harel L, Smetana Z, Varsano I (1997) Treatment of herpes simplex gingivostomatitis with aciclovir in children: a randomised double blind placebo-controlled study. BMJ 314(7097): 1800-1803.

20. Simmons A (2002) Clinical manifestations and treatment considerations of herpes simplex virus infection. J Infect Dis 186: S71-S77.

21. Chilukuri S, Rosen T (2003) Management of acyclovir-resistant herpes simplex virus. Dermatol Clin 21(2): 311-320.

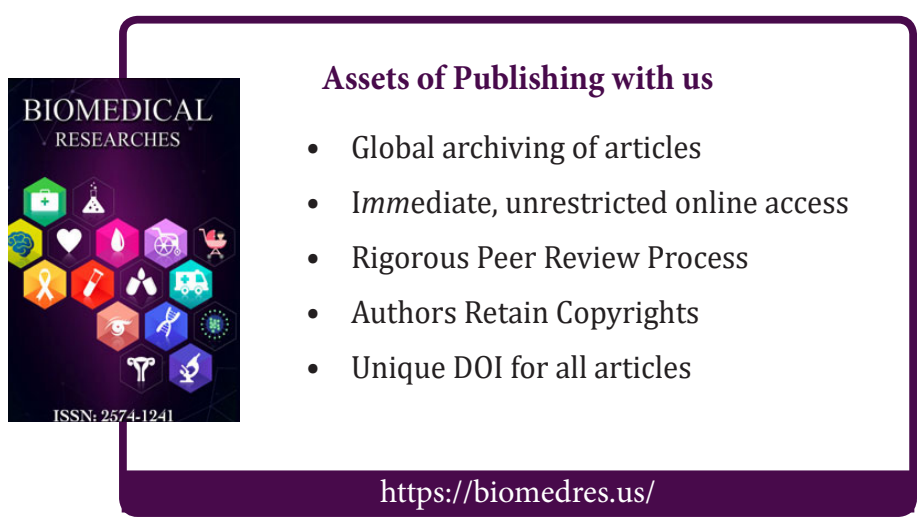

Cite this article: Yadav Karthik D, Pai Anuradha, R Shesha Prasad, Yaji Anisha. Treating the Oral Creeper: Herpes. Biomed Sci\&Tech Res 